\title{
Profiling OVGP Protein in Oviductal Fluid of Kacang Goats in Malang
}

\author{
Herawati $^{1)}$, Aulia Firmawati ${ }^{2)}$, Herlina Pratiwi $^{3, a)^{*}}$, Nurul Isnaini ${ }^{4)}$ \\ ${ }^{1}$ Laboratory of Veterinary Public Health, Faculty of Veterinary Medicine, Brawijaya \\ University. Malang. Indonesia. \\ ${ }^{2}$ Laboratory of Reproduction, Faculty of Veterinary Medicine, Brawijaya University. \\ Malang. Indonesia. \\ ${ }^{3}$ Laboratory of Embryology, Faculty of Veterinary Medicine, Brawijaya University. \\ Malang. Indonesia. \\ ${ }^{4}$ Laboratory of Animal Reproduction, Faculty of Animal Husbandary, Brawijaya \\ University. Malang. Indonesia. \\ a)herlinapratiwi.drh@gmail.com
}

\begin{abstract}
Frozen semen suplemented by Oviduct Specific Glycoprotein (OVGP) is a new way to solve the decrease of in vitro fertility on goats caused by polysperm and to increase efficiency of artificial insemination on goats. Oviduct Specific Glycoprotein has associated with zona pellucida and localized in perivitelline space. Existence of Oviduct Specific Glycoprotein in perivitellin space may be linked to a mechanism that blocks polispermi through vitelin block. Oviduct Specific Glycoprotein can be found in the fluid that was secreted by the oviduct (oviductal fluid). This study was aimed to determine Oviduc Specific Glycoprotein profile in oviductal fluid of Kacang goats Malang district, West Java Province, Indonesia. Oviduct Specific Glycoproteins were collected from oviductal liquid of kacang goats and samples were loaded to 12\% SDS PAGE to determine the molecul weight of Oviduct Specific Glycoprotein, further confirmed by western blot. The result of this study showed that molecule weight of Oviduct Specific Glycoprotein been collected from oviductal liquid was approximately $55-65 \mathrm{kDa}$. After being confirmed by western blotting the molecule weight of Oviduct Specific Glycoprotein were $65 \mathrm{kDa}$.
\end{abstract}

Keyword: Goat Oviductal Fluid, Oviduct Specific Glycoprotein, Frozen Semen

\section{INTRODUCTION}

The oviduct plays a pivotal role in mammalian reproduction, providing an optimal environment for oocyte maturation, sperm capacitation, fertilization, and transport of gametes and embryos (Hunter, 2003). McCauley et al., (2003) mentions oviduct-specific glycoprotein (OVGP) localized in the zona pellucida, perivitelin space, and plasma membrane of oocytes were taken from the oviduct (in vivo) and embryos. This suggests a possible role of the OGP in fertilization and early embryo development. In addition, this study also showed that the oocytes were incubated with OGP had fewer spermatozoa bound to pelusidanya zone (polyspermi). The success of embryonic development occurs when the embryo is protected from excessive spermatozoa and the invasion of microorganisms. In some animals, a mechanical barrier to sperm and micro-organisms carried by the extracellular matrix of the egg cells of the zona pellucida (ZP). Protection is given through the vesicle secretory egg cells called cortical granules (CG), which contains a variety of proteins and enzymes, however, the role of ZP in block fertilization to polyspermi not really understood (Coy et al., 2008). The oviduct-specific glycoprotein related with the zona pellucida 
and localized in space perivitellin (Buhi, 2002). Its presence in perivitellin space may be linked to a mechanism that blocks polyspermi trough vitelin block.

The addition of protein to the frozen semen dilution associated with improved sperm fertility has been studied (Bergeron et al., 2002; Moura et al., 2006; and Goncalves et al., 2008). Goncalves et al., (2008) adding a protein called osteopontin (OPN) to the semen dilution to improve sperm quality. On the other hand, research to confirm addition of oviduct-specific glycoprotein (OGP) in order to increase the numbers of sperm fertility and minimize polyspermi in goat frozen semen has not done. Kacang goats is a local goats that need to be survive and breeding. This study used kacang goats located in Malang district, West Java Province, Indonesia, to get oviduct-specific glycoprotein that will be analized to see its profile and its will be used as candidate of addition to goats frozen semen.

\section{MATERIALS AND METHODS}

\section{Materials}

This study focused on profiling OVGP Kacang goats in Malang district, West Java Province, Indonesia. We used ten female kacang goats reproduction wich has follicle diameter between 3-5 $\mathrm{mm}$ in estrous cycle. Only oviduct derived from animals slaughtered not more than 3 hours may be used (Lapointe et al., 1998).

\section{Collection of OVGP from oviduct fluid of Kacang Goats}

Oviduct fluid collection is done by using the oviduct goat from a slaughterhouse and transported to the laboratory at room temperature $\left(25-27{ }^{\circ} \mathrm{C}\right)$ with physiological $\mathrm{NaCl}$ media. Oviduct then washed twice with physiological saline, placed in a petri disc and then dissection. Fluid collected by flushing using 0,5 cc TCM 199 stock solution to $10 \mathrm{~cm}$ along the oviduct. Results of flushing then centrifuged at $7000 \mathrm{rpm}$ for 10 minunte at $4{ }^{\circ} \mathrm{C}$ to remove cell debris (Coy et al., 2008). Then supernatant results precipitation with ethanol (supernatant mixed with ethanol at a ratio of 1:2), the mixture was then kept at $20{ }^{\circ} \mathrm{C}$ overnight, and the next day centrifuged at 3000 rpm, parts of pellets to be used (Van oss, 1989).

\section{Molecular weight determination of Oviduct-specific Glycoprotein}

Running gel fed into an SDS-PAGE through its walls to below the top line. Then add $1 \mathrm{ml}$ of butanol and allowed to stand for 25 minutes. After the gel solidifies butanol removed and cleaned with PBS and dried with Whatman paper. Then added stacking gel 12\% passing through walls up to the brim and then inserted comb and wait 25 minutes. Furthermore comb taken and the remnants of the gel was cleaned with buffer.Limabelas $\mathrm{mL}$ plus $15 \mathrm{~mL}$ sample buffer laemli put into Eppendorf tube, then heated in a water bath at $100^{\circ} \mathrm{C}$ for 3 minutes. After chilling the samples taken as many as $15 \mathrm{ul}$ included in each well. Protein samples treated with the same standards. After the anode is connected to the lower reservoir and the cathode is connected to the upper reservoir. Power supply is turned on with the electrical current of $30 \mathrm{~mA}, 130 \mathrm{~V}$ for 1 hour. If the gel reaction had reached the bottom reaches a height of $\pm 0.05 \mathrm{~cm}$ from the lower limit of the gel plate. Plat opened and gel taken for staining and washing gel. Staining is done by soaking the gel in a staining solution Comassie Blue R-250 during 30-60 minute. Then do the removal of color 
by soaking the gel in destaining solution and shaken automatically until the gel became clear and the results of electrophoresis photographed or scanned (Aulanni'am, 2005). To further confirm the homogeneity of purification, we performed western blot of purified protein using monoclonal antibody.

\section{RESULT}

The result of this study showed that molecule weight of Oviduct Specific Glycoprotein been collected from Kacang goats oviductal liquid was approximately 55-65 kDa (figure 1). After being confirmed by western blotting the molecule weight of Oviduct Specific Glycoprotein were $65 \mathrm{kDa}$ (figure 2).

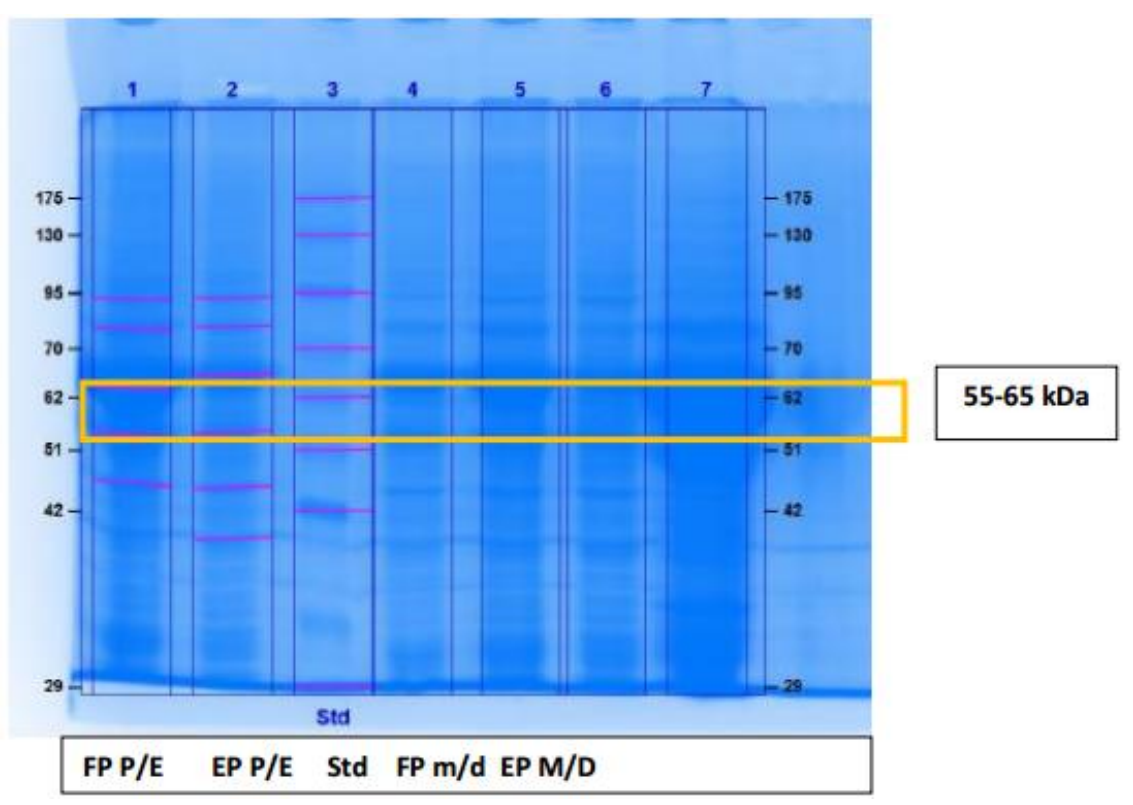

Figure 1. Result of SDS PAGE from oviduct liquids of Kacang Goats. 


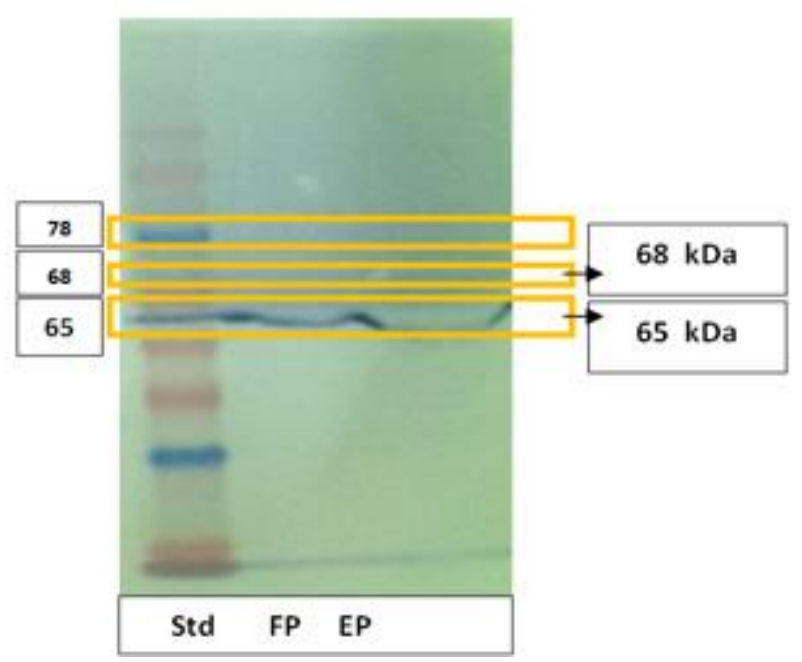

Figure 2. Result of Western Bloting from oviduct liquids of Kacang Goats.

\section{DISCUSSION}

Oviduct fluid collection is done by using the oviduct Kacang goats from a slaughterhouse. In the study Immunolocalisasi and in situ hybridization showed that OVGPs produced only from epithelial oviduct wich not ciliated, a condition in which some species do not produce OVGP in some parts of the oviduct is un known exactly why, despite the lack of production may be related to work of the section (Buhi, 2002).

The predicted molecular weight of secreted OVGP from oviduct of Kacang goats is shown in Figure 1 and 2. The molecular weight was estimated to be the secretion oviduct-specific glycoprotein of Kacang goats oviduct were loaded by SDS PAGE showed a range between 55-65 $\mathrm{kDa}$. This is in line with research conducted by Pradeep et al. (2011) that oviductin obtained from goat oviductal tissue which showed three different bands on SDS-PAGE range of 60-95 kDa. The molecular weight of oviduct-specific glycoprotein oviductal based on one-dimensional SDS-PAGE is specific, but the acid and basic isoelectric variants found in all species checked make different result (Malette and Bleau, 1993). After being confirmed by western blotting the molecule weight of Oviduct Specific Glycoprotein Kacang goats were $65 \mathrm{kDa}$, it was difference with Pradeep et al. (2011) wich find the molecular weight of Specific Glycoprotein goat oviduct was $57.5 \mathrm{kDa}$, calculated from the amino acid sequence. Differences in the molecular weight of the oviductspecific glycoprotein may caused by different types of goats were used, Kacang goats and India goats, wich has difference number of potential O-linked glycosylation site. The larger molecule of Oviduct Specific Glycoprotein can be suggested that it has more large number of potential O-linked glycosylation site.

\section{References}

1. Hunter RH. Reflections upon sperm-endosalpingeal and sperm-zona pellucida interactions in vivo and in vitro. Reproduction in Domestic Animals 2003;38 147-154.

2. McCauley, T.C., W.C. Buhi, G.M. Wu, J. Mao,J.N Caamano, B.A. Didion, and B.N. Day. Oviduct-Specific Glycoprotein Modulates Sperm-Zona Binding and Improves Efficiency of Porcine Fertilization In vitro. Biology of Reproduction 69: 828-834.M. P. Brown and K. Austin, Appl. Phys. Letters 85, 2503-2504 (2004). 
3. Coy P., and M. Aviles. What Controls Polispermi in Mammals, the Oviduct or the Oocyte?. Biological Reviews 2010;85: 593-605.

4. Buhi, W.C. Characterization and Biological Roles of Oviduct-specific, Oestrogen-dependent Glycoprotein. Reproduction 2002;123: 355-362.

5. Bergeron A, Vandenberg G, Proulx D, Bailey JL. Comparison of extenders, dilution ratios and theophylline addition on the function of cryopreserved walleye semen. Theriogenology. 2002; 57(3):1061-71.

6. Moura, A.A.,H. Koc, D.A. Chapman and G.J. Killian. Identification of accessory sex gland fluid proteins as related to fertility indexes of dairy bulls: a proteomic approach. J. Androl 2006; 27: 201-211.

7. Goncalves, R. F., D. A. Chapman, R. P. Bertolla, I. Eder and G. J. Killian. Pre-treatment of cattle semen or oocytes with purified milk osteopontin affects in vitro fertilization and embryo development (abstract). AnimReprod Sci. 2008;108(3-4):375-83.

8. Van oss, CJ. Energetic of cell-cell and cell biopolymer interaction. Cell Biophys 1989; 14: 116

9. Aulanni'am. Protein dan Analisisnya. First Edition. Publisher: Citra Mentari Group. Malang 2005. Pp: 19-27.

10. Lapointe, S., C. Legare, C. Gaudreault, R. Sullivan, and M. A. Sirard. cDNA sequence and deduced amino acid sequence of bovine oviductal fluid catalase. Mol. Reprod. Dev 1998; 51:265-273.

11. Pradeep M.A., J. Jagadeesh, A.K. De, J.K. Kaushik, D. Malakar, S. Kumar, A.K. Dang, S.K. Das, and A.K. Mohanty. Purification, sequence characterization and effect of goat oviductspecific glycoprotein on in vitro embryo development. Theriogenology 75 2011; 1005-1015.

12. Malette B, Bleau G. Biochemical characterization of hamster oviductin as a sulfated zona pellucida-binding glycoprotein. Biochem J 1993; 295:437- 45 